\title{
Effect of cigarette smoking, pulmonary inflammation, and lung disease on concentrations of carcinoembryonic antigen in serum and secretions
}

\author{
RA STOCKLEY, J SHAW, AGW WHITFIELD, TP WHITEHEAD, CA CLARKE, \\ D BURNETT
}

\begin{abstract}
From the Clinical Research Block, General Hospital, Birmingham, and the Medical Services Study Group of the Royal College of Physicians, London
\end{abstract}

\begin{abstract}
A specific radioimmunoassay for carcinoembryonic antigen was used to investigate aspects of its measurement in lung disease. The results confirm that serum carcinoembryonic antigen concentrations are higher in healthy smokers and patients with chronic obstructive bronchitis than in healthy non smokers $(p<0.01)$. Corticosteroid treatment reduced the concentration in nine patients with bronchitis $(\mathrm{p}<0.05)$. Other inflammatory lung diseases (bronchiectasis, pneumonia, fibrosing alveolitis) are not associated with a raised serum carcinoembryonic antigen concentration. The sputum concentrations were about 100 times those found in serum and there was a positive correlation $(r=0.6112 p<0.01)$ between the concentrations in sputum and serum in patients with bronchitis. No preferential rise in sputum concentration was found in current smokers or patients with lung carcinoma $(n=16)$. A higher ratio of carcinoembryonic antigen to albumin concentration $(\mathrm{p}<0.05)$ was, however, found in lavage fluid obtained from the tumour site than in fluid from "normal" lung in the same patients, suggesting an increase in carcinoembryonic antigen secretion in the vicinity of the tumour. Despite this "local" effect the sputum concentration does not, however, appear to be a useful marker of lung carcinoma and the measurement could not be used as a screening test.
\end{abstract}

Carcinoembryonic antigen represents a heterogenous group of glycoproteins with common antigenic determinants. ${ }^{1}$ Its role as a marker of carcinoma of the bowel and an indicator of recurrence has been extensively investigated, with generally disappointing results. Carcinoembryonic antigen is also present in normal lung tissue in small amounts ${ }^{2}$ but has received rather less attention in the assessment of lung disease.

Early studies showed.that serum concentrations of carcinoembryonic antigen were higher in healthy cigarette smokers ${ }^{3-5}$ than in non-smokers. It was suggested that this could be the result of epithelial damage in some smokers, resulting in increased release of the antigen from the lung into the serum. ${ }^{5}$ This suggested a possible role for carcinoembryonic antigen as an indicator of the small proportion of

Address for reprint requests: Dr RA Stockley, General Hospital, Birmingham B4 6NH.

Accepted 10 July 1985 smokers who are "susceptible" to the effects of cigarette smoke and thus to lung disease. This was further supported by the work of Merril et al, ${ }^{6}$ who found two populations of smokers when the concentration of the antigen in lung secretion was measured.

Further studies of carcinoembryonic antigen in serum, ${ }^{7}$ pleural effusions, ${ }^{89}$ and lung secretions ${ }^{1011}$ have been carried out in patients with carcinoma of the lung. Although these reports have suggested that a raised concentration is often associated with carcinoma it is not unique to this lung disease. The interpretation of protein concentrations, particularly in pleural effusions ${ }^{12}$ and lung secretions, ${ }^{13}$ is, however, difficult when inflammation is also present. A further major problem with the measurement of carcinoembryonic antigen in the lung is the presence of nonspecific cross reacting antigen. This is also a glycoprotein found in normal lung tissue, which cross reacts with antibodies to carcinoembryonic antigen. ${ }^{14}$ Since little non-specific cross reacting antigen is present in serum it does not present a problem with 
serum measurements, but its presence in lung tissues could lead to major inaccuracies of carcinoembryonic antigen measurements in lung secretions and pleural effusions.

The present series of studies was carried out to investigate two major aspects of the measurement of carcinoembryonic antigen in lung disease. Firstly, the serum concentration was measured in several groups of subjects to determine whether a raised concentration was a feature of cigarette smoking or related to inflammation in the lung. Secondly, the concentration of carcinoembryonic antigen was measured by a specific assay in lung secretions to determine how much it varied within an individual and its relationship to the serum concentration, smoking, and lung disease.

\section{Methods}

\section{MEASUREMENT OF CARCINOEMBRYONIC} ANTIGEN

Carcinoembryonic antigen was measured in all biological fluids by a radioimmunoassay based on that described by Egan et $a l^{15}$ with minor modifications. In brief, $1 \mathrm{ng}$ carcinoembryonic antigen labelled with iodine 125 (kindly provided by CW Todd, City of Hope National Medical Center, Duarte, California), equivalent to $4.56 \mathrm{kBq} / \mathrm{ng}$, was added to the sample and incubated overnight with a monospecific sheep antiserum (IgG preparation) obtained from the Immunodiagnostic Research Laboratory (Department of Immunology, University of Birmingham). The second antibody (goat antisheep) was added as a solid phase antibody coated cellulose suspension (Sac-Cel, Wellcome Diagnostics, Dartford) and centrifuged at $1000 \mathrm{~g}$ for 10 minutes after 30 minutes' incubation. The supernatant was discarded and the precipitate counted on a Packard 500/c gamma counter and compared with standard solutions of pure carcinoembryonic antigen. The lower limit of detection of the assay was $4 \mathrm{ng} / \mathrm{ml}$ and intra-assay variation $(\mathrm{CV} ; \mathrm{n}=$ 6) was $8.4 \%$ at $5 \mathrm{ng} / \mathrm{ml}, 5.7 \%$ and $12 \mathrm{ng} / \mathrm{ml}$, and $7.7 \%$ at $42 \mathrm{ng} / \mathrm{ml}$. The interassay variability $(\mathrm{n}=3)$ at 130 $\mathrm{ng} / \mathrm{ml}$ was $7.7 \%$.

Serum samples $(200 \mu \mathrm{l})$ were measured neat (assay range 4-128 ng/ml). Sputum samples $(200 \mu \mathrm{l})$ were diluted to 1:32 and 1:64 for most assays, although occasional low values were repeated at 1:16. All samples were run in duplicate.

The specificity of the assay was assessed by using non-specific cross reacting antigen preparation from human spleen (kindly provided by $R$ Smith, Queen Elizabeth Hospital, Birmingham). The details of its preparation have been described previously. ${ }^{16}$

The addition of $1 \mathrm{mg}$ of non-specific cross reacting antigen to $12 \mathrm{ng}$ of carcinoembryonic antigen pro- duced a small rise in the measurement $(6 \mathrm{ng})$. The antibody was subsequently adsorbed by passage down a column of non-specific cross reacting antigen immobilised on sepharose 4B (Pharmacia). The resulting antibody was of lower titre but still showed a slight rise in the carcinoembryonic antigen measurement $(5$ $\mathrm{ng}$ ) when $1 \mathrm{mg}$ of the other preparation was added. These results suggest no detectable cross reactivity of the carcinoembryonic antigen antibody with nonspecific cross reacting antigen in this assay but indicate that the latter preparation contained a small amount of carcinoembryonic antigen.

\section{SERUM STUDIES}

From each subject $10 \mathrm{ml}$ of venous blood was taken, allowed to clot, and centrifuged. The serum was removed and stored at $-70^{\circ} \mathrm{C}$ until subsequent study. Control groups The controls comprised 47 subjects (28 smokers) recruited from the laboratory staff and from outpatients seen six weeks after uncomplicated myocardial infarctions. Twelve of the subjects were women and seven gave a history of mild cough and expectoration related to smoking. None had any other respiratory symptoms and all had normal values in simple spirometric tests (forced expired volume in one second/forced vital capacity $\left.\left(\mathrm{FEV}_{1} / \mathrm{FVC}\right)>65 \%\right)$. Ages ranged from 19 to 78 years (median 50).

Chronic obstructive bronchitis We studied 21 patients with chronic bronchitis related to cigarette smoking ${ }^{17}$ and evidence of irreversible $(<10 \%$ change after bronchodilator) airflow obstruction $\left(\mathrm{FEV}_{1} / \mathrm{FVC}<60 \%\right)$. Only six were current smokers, the remainder having stopped at least one year before the study. Three were women and ages ranged from 42 to 74 (median 60 ). The $\mathrm{FEV}_{1} / \mathrm{FVC}$ ratio ranged from $25 \%$ to $58 \%$ (median 36 ).

Acute pneumonia Twenty patients were studied within three days of admission to hospital because of an acute lower respiratory tract infection. All had a raised temperature and new respiratory symptoms, including cough and purulent secretions. A positive bacterial culture of the sputum was obtained in most cases by routine bacteriological methods. Six of the subjects were non-smokers and had normal lung function (judged by simple spirometry) on recovery. The remainder (10 smokers, four ex-smokers) had chronic obstructive bronchitis as in the previous group.

Idiopathic pulmonary fibrosis (cryptogenic fibrosing alveolitis) Twelve non-smoking patients were studied during the active phase of the disease before steriod treatment. All had classical restrictive lung disease on physiological testing, bilateral basal crackles, and interstitial shadowing evident on the chest radiograph. No cause was identified for the disease in any subject. Bronchiectasis Nine non-smoking patients with radiologically confirmed bronchiectasis who regularly 
produced purulent secretions, were studied whilst in an apparently clinically stable state.

EFFECTS OF REDUCING LUNG INFLAMMATION To determine whether the serum carcinoembryonic antigen concentration was dependent on lung inflammation, two groups of patients were studied before and during treatment known to reduce inflammation (as indicated by reduced protein, transudation from serum) in the lung.

Firstly, we have previously shown that corticosteriod treatment reduces albumin transudation into the lung secretions of patients with chronic obstructive bronchitis in the stable state. ${ }^{18}$ Nine of these patients were included in the present study. Serum was taken while they were receiving placebo treatment and after five days of prednisone in a dose of $40 \mathrm{mg}$ daily. Secondly, we have shown that antibiotic treatment has the same effect when given to patients with purulent bronchiectasis. ${ }^{19}$ The same nine patients were treated for 2 weeks with amoxycillin $250 \mathrm{mg}$ daily or $3 \mathrm{~g}$ (sachets) twice daily and serum was obtained at the end of the course, when the secretions had become mucoid and protein transudation had decreased. ${ }^{19}$

\section{SECRETION STUDIES}

The initial studies were designed to determine the range of concentrations of carcinoembryonic antigen in lung secretions, its variability within subjects, and the relationship to the serum concentration. This investigation was performed in 11 subjects with chronic obstructive bronchitis similar to those described above. All were studied in the stable state at least four weeks after any infective episode. Patients collected sputum (having been trained how to get it as free from saliva as possible) in the first four hours after getting up in the morning for five consecutive days. The samples were ultracentrifuged at $50000 \mathrm{~g}$ for 90 minutes $\left(3^{\circ} \mathrm{C}\right)$ and the supernatant (sol phase) was collected and stored at $-70^{\circ} \mathrm{C}$ until it was analysed. Serum was obtained during the period of sample collection.

Carcinoembryonic antigen was measured as described above and albumin measured by conventional rocket immunoelectrophoresis using a monospecific antiserum (Seward Diagnostics, London) and a known protein standard.

The within and between patient variability (coefficient of variation) of carcinoembryonic antigen in lung secretions was determined.

The relationship between secretion and serum carcinoembryonic antigen was assessed in the samples obtained from these patients by using the method of least squares (two tailed).

Effect of smoking Results for a further 15 patients with chronic obstructive bronchitis were studied, together with the results of the first day sample from the patients before the variability study described above. Of these 26 patients, 16 were current smokers and 10 had given up smoking more than two years previously.

Effect of corticosteroid treatment The patients in whom carcinoembryonic antigen concentration had been studied before and during corticosteroid treatment also provided sputum on the same day. In this way any effect on the serum concentration could be interpreted in the light of secretions in the same subjects.

Saliva studies Because the sputum samples are likely to be contaminated by saliva a small study of the effect of smoking on carcinoembryonic antigen in saliva was also carried out. Unstimulated saliva was collected from 21 normal subjects, nine of whom smoked regularly and 12 of whom had never smoked. The saliva was treated and analysed in the same way as the sputum samples.

Relationship to carcinoma of the lung Sputum carcinoembryonic antigen concentrations from 26 patients with chronic obstructive bronchitis were compared with those from 15 similar patients who had bronchoscopically proved carcinoma of the lung. At bronchoscopy secretions were obtained from both the normal and the diseased lung in 16 patients. All of these patients had obstructing carcinoma of the main or lobar bronchi. Secretions were obtained by instilling $10 \mathrm{ml}$ of sterile saline on to the tumour and aspirating it into a sterile trap. Bronchoalveolar lavage (with $6 \times 20 \mathrm{ml}$ aliquots of sterile saline) was performed on the radiological normal lung (lingula or middle lobe) after the fibreoptic bronchoscope had been gently wedged. Gentle suction was applied after each instillation and the returned fluid was collected into a sterile trap. All samples were filtered through gauze to remove excess mucus and ultracentrifuged at $50000 \mathrm{~g}$ to obtain the supernatant. The lavage fluid was then concentrated with an amicon pressure filtration unit (UMO5 membrane) with a molecular weight cut off of 500 daltons. The albumin and carcinoembryonic antigen concentrations were measured as described above.

STATISTICAL ANALYSIS

The significance of any difference between patient or sample groups was assessed by a two tailed Wilcoxon rank sum test for paired or unpaired data as indicated. The method of least squares (two tailed) was used to determine whether concentrations of carcinoembryonic antigen in secretions and serum were correlated. 


\section{CEA $(\mathrm{ng} / \mathrm{ml})$}

60

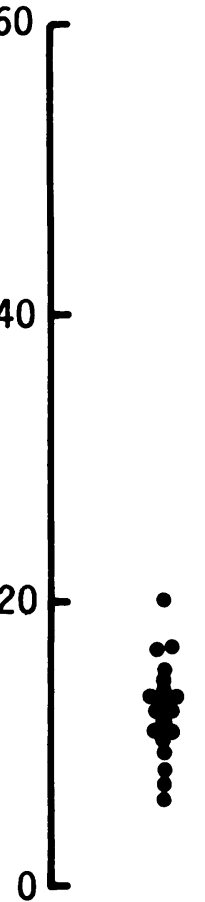

NS

\section{SERUM}

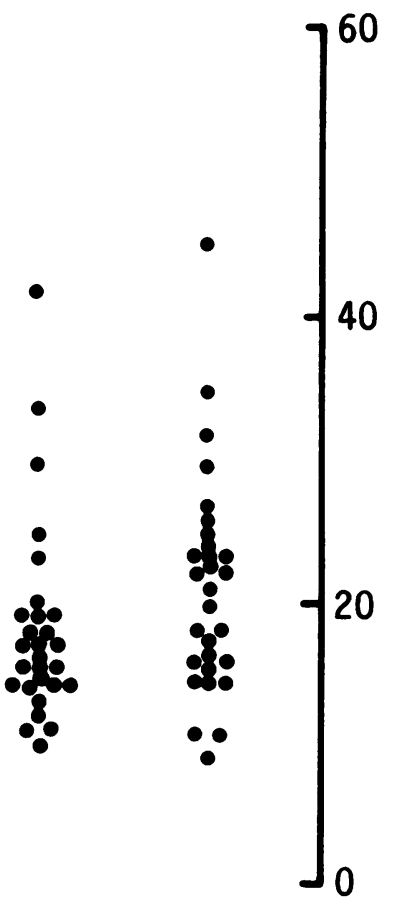

$S$

$\mathrm{OB}$

\section{NORMAL}

Fig 1 Serum concentrations of carcinoembryonic antigen (CEA) for the healthy non-smokers (NS), smokers (S), and patients with chronic obstructive bronchitis $(O B)$. Each point is the result for one subject.

\section{Results}

\section{SERUM STUDIES}

The range of serum carcinoembryonic antigen concentrations obtained for the apparently healthy control subjects was wide (fig 1). The values obtained in smokers were higher $(p<0.01)$ than in the subjects who had never smoked (median for non-smokers 12.0 (range $6.0-20.0) \mathrm{ng} / \mathrm{ml}$; median for smokers 15.5 (range $10-41.5) \mathrm{ng} / \mathrm{ml}$ ).

Similarly, the serum carcinoembryonic antigen concentrations for the patients with bronchitis (median 16.5 (range $9.0-45.0) \mathrm{ng} / \mathrm{ml}$ ) were significantly higher than those in the non-smoking controls and in the control group as a whole $(2 p<0.01)$, although they

were not different from the concentrations in the smoking control subjects alone (fig 1).

The serum carcinoembryonic antigen concentrations in the patients with pneumonia (median 17.5 (range 9.5-40.0) $\mathrm{ng} / \mathrm{ml}$ ), patients with pulmonary fibrosis (median 14.0 (range $10.0-22.5$ ) $\mathrm{ng} / \mathrm{ml}$ ), and bronchiectasis (median 11.25 (range 6.0-20.5) ng/ml) were not different from those obtained in the control group as a whole or in the non-smoking subjects alone.

Reducing lung inflammation had divergent effects on the serum carcinoembryonic antigen. The effect of corticosteroid treatment was to reduce the serum concentration $(p<0.05)$ in seven of the nine patients with bronchitis, the remaining two subjects showing little change. The median value before corticosteroid treatment was 32.5 (range 19.5-216) $\mathrm{ng} / \mathrm{ml}$ and 18.0 (range $0-42.0) \mathrm{ng} / \mathrm{ml}$ during steriod treatment. No effect was seen, however, on serum carcinoembryonic antigen concentration in the nine patients with bronchiectasis after antibiotic treatment (median after treatment 11.5 (range $6.0-17.0) \mathrm{ng} / \mathrm{ml}$ ).

\section{SPUTUM STUDIES}

The concentration of carcinoembryonic antigen in sputum samples were about 100 times greater than the concentrations found in serum. The within subject variability over the five days ranged from $17.5 \%$ to $60.5 \%$. Between patients the variability of carcinoembryonic antigen concentration was much more $\overrightarrow{\overrightarrow{0}}$ constant, ranging from $35.4 \%$ to $55.3 \%$ over the five consecutive days; the mean values are summarised in figure 2 . The serum concentrations in these 11 subjects showed a significant correlation with the sputum concentration during the five consecutive days $(r=0.611$; least squares; $2 \mathrm{p}<0.001)$. These results are summarised in figure 3 .

Sputum from a further 15 patients with chronic bronchitis were included with the results obtained in the 11 patients before the first day of the five day study described above. This gave a similar range (median 1830 (range 660-6000) $\mathrm{ng} / \mathrm{ml}$ ) to that seen for the $11 \frac{\mathrm{T}}{O}$ subjects alone for later comparison with patients who had evidence of a tumour. When the results from these $N$ 26 samples were divided according to whether they $\mathrm{N}$ were from current smokers or ex-smokers (see under 0 "Methods") no difference in sputum carcino- $\underset{ }{\omega}$ embryonic antigen concentration was found. The median value for 16 smokers was 1880 (range 660-6000) $\mathrm{ng} / \mathrm{ml}$ and for 10 ex-smokers 1970 (range 1680-4600) $\mathrm{ng} / \mathrm{ml}$. Corticosteriod treatment had no effect $(2 \mathrm{p}>\stackrel{+}{-}$ 0.1 ) on sputum concentration in the nine bronchitic subjects mentioned previously. The median sputum $\underset{\mathbb{D}}{\stackrel{0}{\mathbb{D}}}$ concentration was 1900 (range $660-4620) \mathrm{ng} / \mathrm{ml}$ before treatment and 2980 (range $980-4540$ ) $\mathrm{ng} / \mathrm{ml}$ during treatment. 
CEA

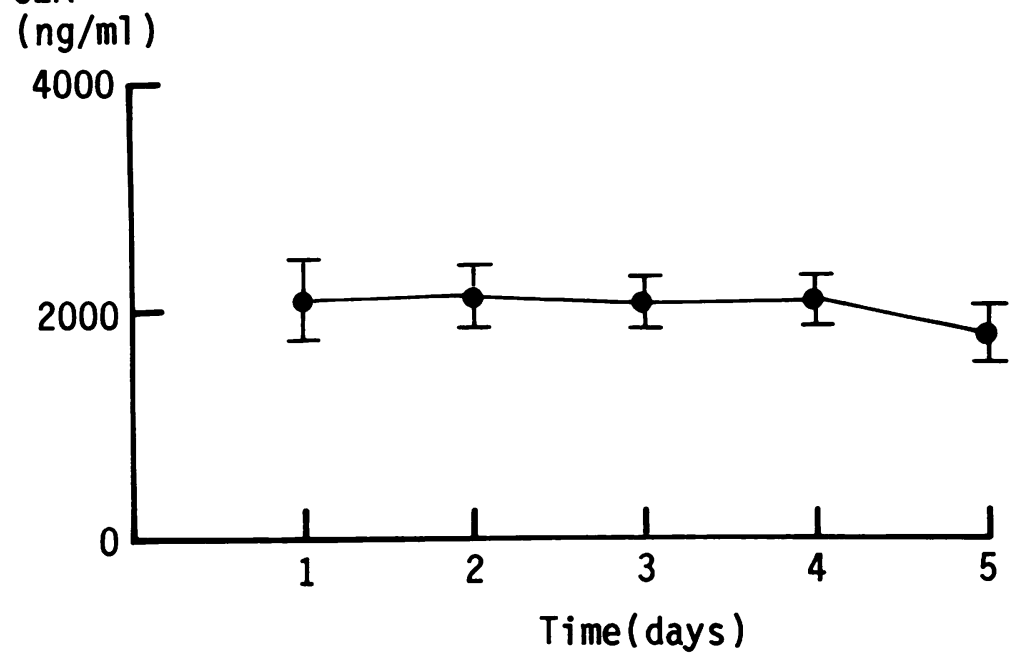

Fig 2 Mean concentrations of carcinoembryonic antigen $(C E A)$ in sputum are shown for the 11 subjects on each of five days. The bar lines indicate one standard error.

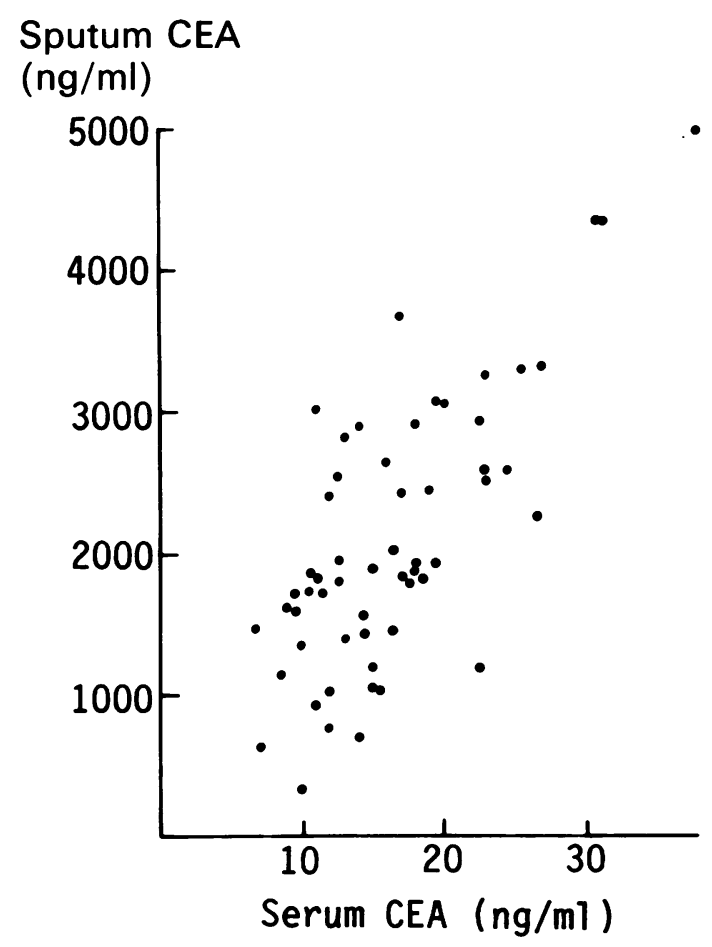

Fig 3 Sputum concentration of carcinoembryonic antigen (CEA) plotted against serum concentration in the same subjects for each of the five days. Each point represents the results from one pair of samples.

\section{SALIVA STUDIES}

The saliva concentrations of carcinoembryonic antigen were about 10 times greater than those found in serum and no difference was found between current smokers and subjects who had never smoked. The median value for nine smokers was 164.0 (range 94.5-208.0) ng/ml and 164.0 (range 32.6-243.5) ng/ml for 12 non-smokers.

\section{CARCINOMA OF THE LUNG}

Sputum carcinoembryonic antigen concentrations from patients with carcinoma of the lung were not higher that those found in patients with chronic obstructive bronchitis alone. The median value for 15 patients where this secretion was collected was 800 (range 180-1540) $\mathrm{ng} / \mathrm{ml}$.

In 16 of the patients carcinoembryonic antigen concentrations were measured in lavage fluid both from the radiologically and bronchoscopically "normal" lung and from the tumour site. The concentrations were higher $(\mathrm{p}<0.01)$ in the tumour washings (median 52.3 (range $2.3-81.7) \mathrm{ng} / \mathrm{ml}$ ) than in the lavage fluid (median 4.15 (range 1.2-49.5) $\mathrm{ng} / \mathrm{ml}$ ).

When the carcinoembryonic antigen result for each secretion was "standardised" for albumin a difference was found between the two secretions $(p<0.05)$. Ten of the 16 patients had a higher ratio of carcinoembryonic antigen to albumin in the secretions obtained from the tumour site. The median values for carcinoembryonic antigen:albumin ratio were lower in lavage fluid (97 $\mathrm{ng} / \mathrm{mg}$ (range 24-840)) than in the tumour site washings (383 ng/mg (79-2280)). 


\section{Discussion}

The present series of experiments was designed to help to clarify several aspects of the relationship between carcinoembryonic antigen and smoke related lung disease. The study was divided into two major parts: firstly, the assessment of serum carcinoembryonic antigen and the effect of bronchial inflammation and, secondly, the potential of measuring the antigen in lung secretions in the identification of smoke related lung disease.

The initial serum studies of carcinoembryonic antigen in apparently healthy subjects confirmed the wide range of values observed previously. ${ }^{20}$ Although most values fell below $20 \mathrm{ng} / \mathrm{ml}$ (the accepted normal range) some were as high as $42 \mathrm{ng} / \mathrm{ml}$. There is, however, controversy about the upper limit of normal and it has been suggested that the normal range should be up to $47 \mathrm{ng} / \mathrm{ml},{ }^{20}$ which includes all of our points. The results also confirm the slightly higher values obtained in smokers. Although this may be due to the inclusion of some individuals who are developing subclinical disease (such as carcinoma of the lung), it has been suggested that the rise is the result of greater "leakage" of the antigen from the lung into the serum of cigarette smokers. ${ }^{5}$ Carcinoembryonic antigen is a large molecule, ${ }^{21}$ but the lungs of smokers show greater permeability than those of non-smokers. ${ }^{22}$ This does not, however, entirely explain the difference since cessation of smoking is known to lead rapidly to normal permeability ${ }^{23}$ and carcinoembryonic antigen concentrations in ex-smokers, although lower, remain higher than those of people who have never smoked. ${ }^{5}$ Furthermore, the results reported here for lung diseases where inflammation, and thus increased permeability, is present did not always show increased serum concentrations of the antigen. Indeed, this is mainly a feature of the smoke associated disease (chronic bronchitis). Therapeutic reduction of lung inflammation and permeability (as assessed by serum protein transudation into lung secretions) by corticosteroids ${ }^{18}$ or antibiotics ${ }^{19}$ failed to have a consistent effect. Although corticosteroids lead to a reduction in serum carcinoembryonic antigen in smoke related disease (obstructive bronchitis), antibiotics had no such effect in a disease not caused by cigarettes (bronchiectasis).

The effect of steroids would fit the hypothesis that the increase in serum carcinoembryonic antigen in bronchitic patients is related to leakage from the lung. Furthermore, this is supported by the lack of effect of corticosteroids on the concentration of carcinoembryonic antigen in lung secretions from the same patients.

Clearly the rise in serum carcinoembryonic antigen in such patients is something unique to the smoking habit and, although it may be related to bronchial inflammation, it is not a feature of inflammation alone. It remains possible that the steroid effect is mediated independently of bronchial inflammation, perhaps by an effect on carcinoembryonic antigen metabolism or catabolism at tissue level. Further studies will be necessary to confirm our finding and to help to define the mechanism.

In the second part of the study we further evaluated the use of carcinoembryonic antigen in secretions as a marker of susceptibility to disease related to cigarette smoking, with progression of disease, and as an indicator of the presence of lung cancer.

The results for sputum showed the concentrations to be much higher than in serum. The day to day variability of an individual subject and the variability between subjects was similar to that for other sputum proteins. ${ }^{24}$

The higher concentrations of carcinoembryonic antigen in secretions than in serum suggest that it is concentrated in the secretions, either by local production or by preferential transport. ${ }^{13}$ The conventional techniques of standardising results of locally concentrated proteins for the albumin in the secretion has been shown to increase variability. ${ }^{25}$ The present study confirmed this for carcinoembryonic antigen, and standardising for albumin increased both within and between patient variability (results not shown). Nevertheless, some variability of concentration remains even in a single subject. This remains unexplained but may be partly due to the mixed nature of the secretions and to contamination by saliva during expectoration. The saliva concentrations are generally about $10 \%$ of the sputum concentration and thus such contamination would lead to variable dilution of the carcinoembryonic antigen in sputum.

Interestingly, a correlation was found between the concentrations of carcinoembryonic antigen in sputum and serum. To our knowledge this is the first such demonstration. It suggests that the antigen concentration in the lung, rather than other sites such as the bowel, may be a major determinant of the serum concentration in such patients. In this respect it is clearly important for the interpretation of the serum changes found (see above) that steroids did not affect the sputum concentration.

The range of sputum concentration of carcinoembryonic antigen in patients with obstructive bronchitis was wide and no difference was found between current smokers and ex-smokers. If the concentration reflects continuing lung damage in an individual smoker, a fall might be expected to occur once smoking and hence disease progression have ceased. This lack of difference fails to clarify the hypothesis proposed by Merril et $a^{6}$ that a raised concentration of carcinoembryonic antigen in secretions indicates the 
susceptible population among smokers. The present study was carried out on a population of subjects with established smoke related lung disease. It thus remains possible that although the carcinoembryonic antigen concentration in these subjects is independent of the current smoking habit, the concentration is already raised because of development of their disease or of its presence. Further studies of bronchitic subjects with normal lung function will help to clarify this point.

The results on saliva, however, were obtained from healthy subjects and no difference was found between smokers and non-smokers. But this does not yet negate the use of carcinoembryonic antigen in this secretion as a marker of the susceptible smoker, since only a small proportion of smokers fall into this category. Clearly larger numbers, other secretions, and longer follow up will be necessary to clarify this point.

The results from patients with carcinoma were generally disappointing. The sputum values were similar to those from patients with chronic bronchitis. Although some of the bronchitic patients may be developing carcinoma, the complete overlap of results suggests this is not a useful marker in any subject since carcinoembryonic antigen is probably a smoking related and not a disease related protein. It remains possible that none of the tumours studied here was releasing, or even contained, any appreciable amount of the protein. The tumours studied were a mixture of all types but even separation into individual groups did not affect the results (data not shown).

The alternative explanation is that secretions derived from the tumour are overwhelmingly mixed with secretions from non-affected parts of the lung. To investigate this further we studied secretions from both lungs in some subjects. To obtain strictly comparable samples is difficult since lavaging patent and obstructed bronchi will produce samples from different regions of the lung and provide different volumes of returned fluid. We chose a limited lavage technique for the obstructed bronchi and conventional bronchoalveolar lavage for the "normal" lung.

The concentrations of carcinoembryonic antigen were higher in the lavage fluid from the tumours than in the bronchoalveolar lavage fluid. Such differences have, however, been found before between bronchial lavage fluid (and hence a small volume) and bronchoalveolar lavage fluid ${ }^{26}$ and the finding merely represents a problem of secretion dilution with lavage fluid. In this instance comparison with albumin can be of use in determining differences between secretions from different regions of the lung. ${ }^{1326}$ With this technique the ratio of carcinoembryonic antigen to albumin was greater in the tumour lavage fluid than in the fluid from the other lung for the group as a whole.
Thus mixing of secretions could perhaps lead to a lower carcinoembryonic antigen concentration in these patients and would suggest that much of the expectorated antigen is from elsewhere in the lung. The results again suggest that a lack of clear difference in the sputum results is due to the fact that few of the tumours are producing or contain sufficient of the protein to alter the overall secretion pattern. This cannot be clarified without immunohistochemical studies and culture of the tumour tissue. Even if this is the case the results suggest that carcinoembryonic antigen in secretions is unlikely to be useful in identifying most tumours by simple screening tests. Indeed, even though a statistical difference in the ratio of carcinoembryonic antigen to albumin was found locally at the tumour site such a difference was not a constant feature, and it is thus of limited value even in these more invasive studies.

In conclusion, the serum carcinoembryonic antigen concentration has been shown to be related to the secretion concentration of the antigen and the presence of smoke related disease. It has not proved a useful marker of carcinoma of the lung in the secretions and hence would not be viable as a screening test. The potential of carcinoembryonic antigen as a marker before the development of lung disease has yet to be assessed.

This work was supported by the Central Birmingham Health District Endowment Fund, the General Hospital bicentenary appeal fund, and Bencard. RAS is a Wolfson research fellow of the Royal College of Physicians of London. We thank K Roberts for typing.

\section{References}

1 Coligan JE, Henkart PA, Todd CW, Terry WD. Heterogeneity of the carcinoembryonic antigen. Immunochemistry 1973;10:591-9.

2 Pusztaszeri G, Mach J-P. Carcinoembryonic antigen (CEA) in non digestive cancerous and normal tissues. Immunochemistry 1973;10:197-204.

3 Stevens DP, Mackay IR, Busselton Population Studies Group. Increased carcinoembryonic antigen in heavy cigarette smokers. Lancet 1973;ii:1238-9.

4 Stevens DP, Mackay IR, Cullen KJ. Carcinoembryonic antigen in an unselected elderly population: a four year follow-up. $\mathrm{Br} J$ Cancer 1975;32:147-51.

5 Clarke C, Hine KR, Dykes PW, Whitehead TP, Whitfield AGW. Carcinoembryonic antigen and smoking. $J$ Roy Coll Phys Lond 1980;14:227-8.

6 Merril WW, Goodman M, Matthay RA, Naegel GP, Vandevoorde JP, Myl AD, Reynolds HY. Quantitation of carcinoembryonic antigen in lung lining fluids of normal smokers and non smokers. Am Rev Respir Dis 1981;123:29-31.

7 Laurence DJR, Stevens U, Bettelheim R, et al. Role of plasma carcinoembryonic antigen in the diagnosis of gastrointestinal mammary and bronchial carcinoma. $\mathrm{Br}$ Med J 1972;iii:605-9. 
8 Rittgers RA, Loewenstein MS, Feinerman AE, Kupchik HZ, Marcel BR, Koff RS, Zamcheck N. Carcinoembryonic antigen levels in benign and malignant pleural effusions. Ann Intern Med 1978;88:631-4.

9 Booth SN, Lakin G, Dykes PW, Burnett D, Bradwell AR. Cancer associated proteins in effusion fluids. J Clin Pathol 1977;30:537-40.

10 Lemarie E, Lavandier M, Renoux M, Renoux G. Carcinoembryonic antigen in bronchoalveolar lavage fluid. N Engl J Med 1980;303:586-7.

11 Goldstein N, Lippmann M, Goldberg S, Fein A, Shapiro B, Leon SA. Simultaneous determination of tumour markers in bronchoalveolar lavage fluids and blood of patients with malignant or benign lung disease [abstract]. Am Rev Respir Dis 1984;129:(No 4 part 2):A68.

12 Burnett D, Booth SN, Bradwell AR. Fibrin/fibrinogen degradation products in pleural exudate. Lancet 1976;ii:523.

13 Stockley RA. Measurement of soluble proteins in lung secretions. Thorax 1984;39:241-7.

14 Von Kleist S, Chavanel G, Burtin P. Identification of an antigen from normal human tissue that crossreacts with the carcino-embryonic antigen. Proc Natl Acad Sci 1972;69:2492-4.

15 Egan ML, Lautenschleger JT, Coligan JE, Todd CW. Radioimmune assay of carcinoembryonic antigen. Immunochemistry 1972;9:289-99.

16 Smith SR. Studies in metabolic human breast cancer. MD thesis, University of Birmingham, 1982.

17 Medical Research Council Committee on the Aetiology of Chronic Bronchitis. 1965. Definition and classification of chronic bronchitis. Lancet 1965; i:775-9.

18 Wiggins J, Elliot JA, Stevenson RD, Stockley RA. Effect of corticosteroids on sputum sol-phase protease inhibitors in chronic obstructive pulmonary disease. Tho$\operatorname{rax}$ 1982;37:652-6.

19 Stockley RA, Hill SL, Morrison HM. Effect of antibiotic treatment on sputum elastase in bronchiectatic outpatients in a stable clinical state. Thorax 1984;39:414-9.

20 Hine KR, Leonard JC, Booth SN, Dykes PW. Carcinoembryonic antigen concentrations in undiagnosed patients. Lancet 1978;ii:1337-40.

21 Coligan JE, Lautenschleger JT, Egan ML, Todd CW. Isolation and characterisation of carcinoembryonic antigen. Immunochemistry 1972;9:377-86.

22 Jones JG, Minty BD, Lawler P, Hulands G, Crawley $\mathrm{JCW}$, Veall N. Increased alveolar epithelial permeability in cigarette smokers. Lancet 1980;i:66-8.

23 Minty BD, Jordan C, Jones JG. Rapid improvement in abnormal pulmonary epithelial permeability after stopping cigarettes. $\mathrm{Br}$ Med $J$ 1981;282:1183-6.

24 Wiggins J, Stockley RA. Variability in sputum sol phase protein in chronic obstructive bronchitis. The value of using albumin for standardization. Am Rev Respir Dis 1983;128:60-4.

25 Wiggins J, Stockley RA. Variability in the secretory $\operatorname{IgA}$ system in sputum sol phase in stable chronic obstructive bronchitis. Eur J Respir Dis 1984;65:433-40.

26 Wiggins J, Hill SL, Stockley RA. Lung secretions solphase proteins: comparison of sputum with secretions obtained by direct sampling. Thorax 1983;38:102-7. 